not been recorded there for many years. The northern section of Weeting Heath consists largely of chalky grassland forming a thick turf with pine trees scattered in groups. The more barren parts of the heath have yielded a very rare spider (Oxyptila scabricula), and another spider (Philodromus collinus) occurs only at two other places in Britain.

Applications for permits, which will be necessary for those who wish to visit the reserve, to undertake research and to collect specimens of animals or plants, should be addressed to the Regional Officer for East Anglia, The Nature Conservancy, Bishopgate, Norwich.

Knocking $\mathrm{Hoe}$ in Bedfordshire is a small relic of a particular type of close-grazed chalk downland turf, which is rapidly disappearing under the present system of land use in Britain. The turf is thought to be of very ancient origin, and has probably remained undisturbed by cultivation at least throughout historic times. There is a rich flora of low-growing chalk downland species. The reserve has been established under a Nature Reserve agreement with the owner, Mr. L. T. Franklin. It will continue to be used for sheep grazing, as this is considered to be the best way to preserve the present composition of the sward. Access to the reserve will be by permit only, of which only a very limited number will be issued. Applications can be made to the Regional Officer for the South-East, The Nature Conservancy, 19 Belgrave Square, London, S.W.I.

\title{
POPULATION STUDIES OF THE COMMON EARWIG
}

\begin{abstract}
$\mathrm{D}$ URING the summer of 1956 , there was a plague of the common earwig (Forficula auricularia Linn.) in the garden of 28 Yarborough Road, Lincoln. Traps were erected to catch the earwigs and large numbers were caught. P. F. Baker (Trans. Lincolnshire Naturalists Union, 14, No. 2; December 1957) made a study of the relative numbers of males and females in the population and of the percentage of the population consisting of the variety with large elliptical forceps, known as form forcipata Steph. Later, it was decided to investigate the distance moved by different individuals in the population; this was done by a marking experiment.

The final total of 337 males and 332 females showed that during August and September 1956, in the earwig colony studied, males and females were present in almost equal numbers.

The males were found to be the most variable: the commonest varieties being those in which onehalf of the calipers differed markedly in curvature from the other. This was found in both typical and form forcipata males. Two specimens were caught which from their external appearance seemed to be gynandromorphs.

Previous work on population statistics had led to the belief that earwigs were migrating from one part of the garden to another and it was decided to assess the movements of separate individuals in the population. To investigate movement an evenly
\end{abstract}

spaced network of traps was set up over the area so that each trap was about one yard from its immediate neighbours. Separate pots were labelled and all insects caught in any particular pot were marked on the elytra with oil paints of a colour characteristic of the pot.

To mark the insects during a period of relative quiescence-from general observations the earwig seemed to be active at night and inactive, or nearly so, during the daylight hours-an actograph was used. This relied on a displacement of equilibrium as the insect moves in a cage ; a mark is registered on a drum. In this way the earwig was shown to be entirely nocturnal, commencing activity at dusk and continuing to dawn. For this reason removal of the insects from the traps was carried out in the daytime ; these earwigs were then marked with oil paint and released at the base of the trap in which they were caught. The marking, to be recognizable, usually lasted for one retrapping only; other earwigs ate the oil paint off their fellows.

Recaptures of marked individuals made up 12 per cent of the whole.

The results showed small daily migrationary trends. In this case conditions were ideal and food was not scarce. It is known, however, that the common earwig will, under special environmental conditions or when food is scarce, migrate in thousands in search of new grounds.

\section{DIRECTING YOUNG SALMON}

$\mathrm{R}$ ESEARCH on the methods of guiding young Pacific salmon while migrating downstream have recently been described by J. R. Brett and D. F. Alderdice (Fisheries Research Board of Canada. Bulletin No. 117 : Research on Guiding Young Salmon at Two British Columbia Field Stations. Pp. viii +75. Ottawa: Queen's Printer, 1958. 75 cents).

The first experiments, in 1953 , were performed in a large divided trough using captive sockeye yearlings. These tests were intended to survey broadly the possibilities of using various techniques, including light, sound, air bubbles, curtains of hanging chain, odours, dye releases and differences in water velocity as means of guiding young fish. Significant deflexion resulted from the use of a relatively large area of illumination at night, a band of rising air bubbles or bursts of dark dye during the day, and strands of chain hung vertically during both day and night.

Further trough experiments, in 1954, on the use of hanging chain demonstrated that the maximum distance between strands which produced a deflexion of 75 per cent or more fish through an angle of $45^{\circ}$ was 4 in. Apart from its light-reflecting quality, the type of chain was found to be unimportant. The sensory stimulus causing the avoiding reaction was found to be primarily visual. Slow oscillation of the chain increased the deflexion of sockeye. Coho yearlings were not significantly deflected.

In conjunction with the trough experiments, a limited number of field tests using a 56 -ft. oscillating chain deflector (144 oscillations a minute) in the 
Lakelse River, British Columbia, proved that the technique had promise for guiding a natural run of young sockeye. At right angles to the direction of water flow a maximum of 79 per cent deflexion was achieved. However, the barrier was subject to considerable penetration if conditions were not ideal ; coho were still not effectively deflected.

A number of modifications was introduced in the 1955 deflector. The chain was replaced by cables which were suspended from a continuous moving belt. The belt travelled across-stream, reversing at the entrance to the trap. Various intervals and rates of travel (to a maximum of 12 in./sec.) were tested. The combinations which proved most effective included an interval between strands of not more than 6 in., and rates of travel from 8 to $12 \mathrm{in}$./ $\mathrm{sec}$. In these circumstances an average of 92 per cent of sockeye and 59 per cent of coho were deflected.

In addition to changes in the defiector, a new opening or by-pass to the inclined-screen trap was built. The particular features of the by-pass were a reduction of visual cues in the entrance by using smooth, painted surfaces, a gradual acceleration of the incoming water to a velocity equal to or just exceeding the maximum swimming speed of the migrants, and the presence of cross-reflecting mirrors. Although the first model had limitations, it improved the trapping of deflected fish and permitted a good numerical assessment of the deflector.

The final tests were conducted in Hoolnose Creek during the spring of 1956. Pink, chum and coho fry, as well as sockeye and coho yearlings, migrate down this small stream. The same deflector was used, with additional features of smaller, weighted cables, a minimum interval of 2 in. between strands, low direct-current charging of the moving cables, and a 3 -ft. wide sheet of metal on the stream bed, painted white to reflect light incident on the surface. The reduction in spacing was introduced to scale down the interval dimensions to a more appropriate size for fry. Also, by adding an electric charge, a combination of stimuli was presented which was thought would be more effective.

No success was obtained in guiding any of the fry. However, both coho and sockeye fingerlings were deflected at 95 per cent level and higher.

The investigations showed that new methods must be sought for the guiding of salmon fry. For yearlings, a full-scale test is desirable under conditions which approximate to reservoir characteristics of large dams.

\title{
A NEW APPROACH TO THE CHEMOTHERAPY OF CANCER
}

\author{
By Dr. M. B. SAHASRABUDHE \\ Biology Division, Atomic Energy Establishment, Trombay; Indian Cancer Research Centre, Parel, Bombay, India
}

$\mathrm{T}$ HE use of antimetabolites as a means of controlling cancer was first investigated by Sidney Farber ${ }^{1}$ in 1948, using folic acid antagonists. Since then a number of compounds having antagon. istic properties against such essential metabolites as purines $^{2}$, pyrimidines ${ }^{3}$, vitamins ${ }^{4}$ and glucose ${ }^{5}$ have been tested. The main drawback of the antimetabolites tested so far has been that they interfered with the normal processes also, and as such exhibited toxic effects. Further, some of the tumours develop resistance to the drugs. The former difficulty might be overcome by using antimetabolites against a specific substance or substances having an important function in tumours only; but in spite of the large amount of work, such a qualitative difference between a tumour and normal tissue has not so far been discovered. There are, however, quantitative differences which might be exploited with advantage in the chemotherapy of cancer.

One of the striking differences between normal and malignant tissues is the active cell proliferation accompanied by high rate of synthesis of nucleic acid in neoplastic tissues. This high rate, however, is not a characteristic solely of neoplastic growth. Normal embryonic tissues are also known to exhibit active nucleic acid synthesis without any evidence of neoplastic transformations. Hence embryonic and tumour tissues are similar in so far as active cell proliferation and nucleic acid synthesis are concerned; but whereas embryonic growth comes to a stop after a while, the tumour continues to grow apparently without any control whatsoever. In the present communication an attempt is made to explain these differences in the light of existing knowledge, and to suggest ways and means of exploiting these differences to control cancer growth.

\section{Regulation of Normal Growth by Biological Feed-Back Mechanism}

To maintain the rapid rate of synthesis of nucleic acid, two things are essential : (i) a continuous flow of precursors and (ii) an unrestricted supply of energy. In the biological system, the energy is usually generated in the Krebs tricarboxylic acid cycle through the stepwise degradation of metabolites into carbon dioxide and water. Pyridine nucleotides have an important role in this connexion in the hydrogen transport system, and thus indirectly participate in the energy production via the tricarboxylic acid cycle. One of the precursors of pyridine nucleotides is adenine, which is also a precursor of nucleic acids. Since the same substance (adenine) is required for the synthesis of nucleic acid and also of pyridine nucleotide, a sort of chemical competition is set up between the two for appropriation of adenine.

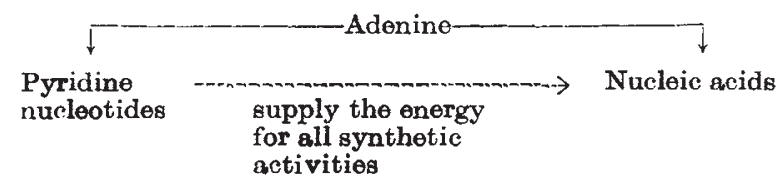

In an actively growing tissue, unless larger amounts of adenine are made available from the metabolic pool, it (adenine) is likely to be used for the synthesis of nucleic acid and very little will be left for the synthesis of pyridine nucleotides. This seems to be corroborated by published work ${ }^{6}$ on the levels of pyridine nucleotides in various tissues (see Table 1). 